\section{Need For Education, Not Just Training}

\section{Barbara Foster, Microscopy/Marketing \& Education}

Microscopy is unique among its analytical counterparts: it requires a hand-eye-brain coordination not needed in any other type of analytical instrumentation. On one hand, manufacturers of microscopes and auxiliary technologies are working to make systems seamless, transparent, and easier to use. On the other hand, microscopists, even those who will use the microscope as routine tools, need to be knowledgeable in their core disciplines as well as fluent in microscopy and sample preparation. It is not enough that a the person running a microscope be trained to "push this button; turn this knob". Especially as we move into the next millennium, it will become increasingly important to understand the light/matter, electron/matter, or probe/matter interactions which occur when examining a specimen. Microscopists of all descriptions will need to know how to optimize both the sample and the technology, how to interpret the information presented by the image, and how to separate artifact from true information. To compound the problem, the convergence of computer, diverse software packages, microscope, camera, and analytical techniques is producing a new type of multiple level information which, in turn, requires expertise in multiple disciplines. All these factors dictate a need for better education, not just training.

Training implies a basic knowledge of instrumentation, the sort of "turn this knob, push this button" exposure typical of a new instrument installation. Education suggests a more thorough grounding in beam/sample interaction and instrument construction. It involves building a strong foundation of principles which can be used for more creative problem solving. The need for education is made more critical by three challenges: the loss of veteran microscopists, the dawn of the digital age, and the convergence of microscopy with other analytical technologies.

\section{A Quarter Century Hemorrhage Of Experience}

Good microscopists are not only facile with sample preparation and instrument operation, as they work, they acquire a mental library of images and a repertoire of "tricks of the trade". Death, downsizing, promotion, and retirement are robbing microscopy of this valued resource. The result is a pool of less experienced practitioners. Especially in today's fluid industrial environment, inexperienced analysts are being thrust into the microscopy lab without much support. In all too many cases, upper management fails to understand the need for time-ingrade and on-going education. Dr. John Reffner, now with Sensor Technologies (Danbury, CT), once suggested, tongue-incheek, that no one under the level of Ph.D be allowed to use a light microscope. This comment is startling, knowing his long time and ardent support of better education in microscopy. When asked why he took this position, he observed that, with the higher education requirement, lab managers would take microscopy seriously.

Interestingly, microscopists are part of this problem. Whether in industry or academe, we need to make upper management aware of the impact of microscopy. At the risk of being crass, economics are the reality of today's world. In industry did microscopy provide the solution that got the production line up and running again? Did it save the company a million dollar law suit? In academe, did your images bring in a new research grant? Are your students going on to more prestigious employment because microscopy was part of your curriculum?

\section{Enter The Digital Age}

In addition to proficiency in microscopy and a core discipline, today's microscopists face a tangle of digital accessories from computers and cameras to image processing and analysis software and the web. In all technology areas, the microscope has become the front end of an imaging system, requiring the microscopist to understand the electronic side of image formation and the implications of electronic processing. The digital age also raises new questions in terms of the ethics: how far can one process an image without losing its scientific validity? Here again, a good education provides the foundation for good practice.

While the digital age presents its own set of challenges, it might also provide important solutions. The quarter of a century of downsizing has had an interesting fall-out in central service labs. In many cases, there is now more equipment than there are people to run it. Since all microscopes can be computer controlled to a greater or lesser extent, real-time Internet telemicroscopy, not just telepresence, may offer new access to that equipment. Some electron microscopy companies (i.e., LEO) currently offer full diagnostics over the Internet. It is a simple step to open that interface to anyone who wants to run the microscope remotely. Other commercial entities, such as Illumea, are developing proprietary algorithms to control light microscopes over the Internet so that a remote user can image the whole slide and navigate in real-time, without any distracting lag.

The implications within companies, and across the globe, are profound. It means that sophisticated equipment which now lies dormant can be used by anyone within the company or anywhere in the world. The good news: increased profitability for central service facilities. The challenge: yet another level of education for the broader population of Internet microscopists to take advantage of this opportunity. Additionally, this new community of microscopists will need to know how to mine the Internet and other resources to gather the complementary data necessary to complete the picture.

\section{A New Dimension: \\ Convergence Of Analytical Technologies With Microscopy}

Convergence and integration have become the flagships of instrument development. A quick walk around the show floor at this year's PITTCON meeting underscored this concept. Raman analysis combined with confocal is becoming routine. Several companies have integrated the powerful chemical analysis of FTIR with light microscopy for conventional imaging. Thermal analysis is popping up in all areas, from light microscopy to electron and environment SEMs to atomic force microscopes. As the battery of instrumentation expands, the well-rounded microscopist will need to understand how these techniques work together to provide the various perspectives on their problem.

\section{Where Are We Today?}

Microscopy/Marketing \& Education has been conducting market research for nearly a decade at a wide variety of technical meetings. Table 1 details some recent findings in terms of where microscopists see the need for education. These findings point out the complexities of offering good education to the broad microscopy audience.

First, microscopy is highly heterogeneous. MME's research indicates that there are two key audiences in microscopy: those who consider themselves microscopist and follow meetings such as Microscopy \& Microanalysis (M\&M), versus those who consider microscopy a tool and follow more discipline-focused meetings 
such as ACS, the American Society for Materials, SEMICON West, Experimental Biology, Cell Biology, and Neuroscience. Logically, this heterogeneity carries over into the most critical areas for training.

Secondly, video/digital imaging and the concomitant image processing and analysis rank highly among most groups. The audience at MSAM M M meetings is a good cross-section of the biological and materials science components of this industry. It also represents a good balance between industry and academe. Note the especially high ranking of image analysis in this group; a direct effect of the evolution of the digital age.

Finally, no matter which group is surveyed, each recognizes the impact on productivity of better education. The next big question: is it available? And if so, where.

\section{The Solutions}

An informal request to two listservers provided a resounding answer to these questions. Over 40 responses poured in over the brief period of two days. Two colleges, San Joaquin Delta (Stockton, CA) and Madison Area Technical College (Madison, WI) each offer full 2-year technician's degrees in electron microscopy. San Joaquin Delta also includes optical and scanning probe microscopies. A number of other academic sites offer one semester courses in SEM and/or TEM. The average class size for SEM seems to be about 10 and for TEM, about 5. Dr. Laurence Marks (Northwestern University Department of Materials Science and Engineering) reported that "[there is a] microscopy course in almost every materials science department in the county." Their department boasts five: freshmen SEM, senior SEM/TEM, graduate level TEM, high resolution EM and diffraction, and advanced analytical EM.
Purdue's Dr. J. Paul Robinson runs a graduate course in confocal microscopy and $3 \mathrm{D}$ imaging. For a peek, request their educational and well-illustrated CD-ROM.

Several universities have also become well-known for their workshop programs. Lehigh and New Paltz are both well known for their SEM seminars while the Marine Biological Labs (Woods Hole, MA) have built a strong reputation for light microscopy in the biological sciences. The University of North Carolina offers the "Carolina Workshops" under Drs. LeMasters, Salmon, and Jacobson, including Light Microscopy for Biomedical Sciences and an integrated course which covers conventional brightfield imaging

\section{Continued on following page}

Table 1: Many groups recognize the imapct of training on productivity. As expected, specific needs vary by discipline and application area

\begin{tabular}{|l|r|r|r|r|r|r|r|}
\hline \multicolumn{1}{|c|}{ Topic: } & $\begin{array}{c}\text { ACS* } \\
96\end{array}$ & $\begin{array}{c}\text { ExBio* } \\
97\end{array}$ & $\begin{array}{c}\text { Cell Bio* } \\
98\end{array}$ & $\begin{array}{c}\text { MSA }^{*} \\
95\end{array}$ & $\begin{array}{c}\text { M\&M* }^{*} \\
96\end{array}$ & $\begin{array}{c}\text { M\&M }^{*} \\
97\end{array}$ & $\begin{array}{c}\text { M\&M* } \\
98\end{array}$ \\
\hline Image Analysis & $17 \%$ & $27 \%$ & $28 \%$ & $45 \%$ & $41 \%$ & $44 \%$ & $45 \%$ \\
\hline Light Microscopy & $20 \%$ & $14 \%$ & $12 \%$ & $10 \%$ & $13 \%$ & $14 \%$ & $14 \%$ \\
\hline Fluorescence & $11 \%$ & $33 \%$ & $28 \%$ & $8 \%$ & $7 \%$ & $11 \%$ & $12 \%$ \\
\hline SEMTEM & $17 \%$ & $2 \%$ & $4 \%$ & $9 \%$ & $8 \%$ & $7 \%$ & $11 \%$ \\
\hline WDS/EDS & $2 \%$ & $1 \%$ & $<1 \%$ & $11 \%$ & $14 \%$ & $11 \%$ & $13 \%$ \\
\hline Confocal & $6 \%$ & $21 \%$ & $26 \%$ & $12 \%$ & $9 \%$ & $15 \%$ & $16 \%$ \\
\hline Scanning Probe & $9 \%$ & $2 \%$ & $4 \%$ & $9 \%$ & $8 \%$ & $7 \%$ & $11 \%$ \\
\hline
\end{tabular}

*LEGEND: ACS: American Chemical Society 1996 ExBio: Experimental Biology (FASEB) 1997 CellBio: American Society for Cell Biology 1998 MSA: Microscopy Society of America 1995 M\&M: Microscopy \& Microanalysis 1996, 1997, 1998

\section{Do You Need to Manage}

\section{STRESS, STRAIN, TENSION AND FATIGU}

Introducing A New Data Acquisition System
Designed Specifically For The Parameters Of
Mechanical Testing
Featuring MTESTWindows ${ }^{T M}$ Software
Now Available For FULLAM TENSILE SUBSTAGES
For SEM, SPM or Benchtop Use
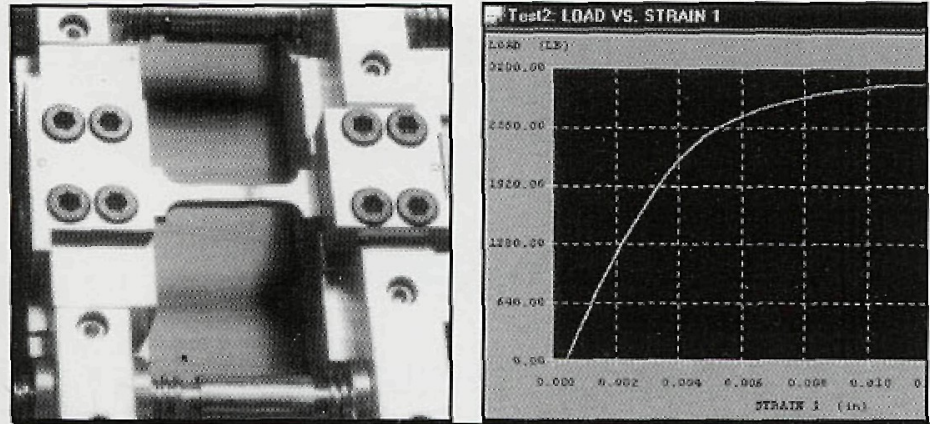

ERNEST F. FULLAM, INC.

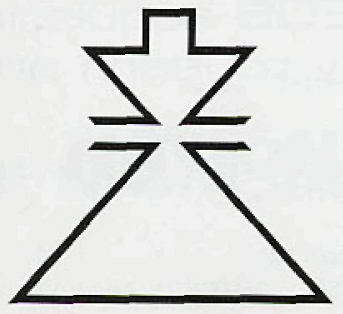

900 Albany Shaker Road Latham NY 12110-1491

Tel: $518785-5533$

FAX: $518785-8647$

Email:sales@fullam.com www.fullam.com 


\section{Need For Education, Not Just Training Continued from proceeding page}

as well as fluorescence, confocal microscopy, and the new multi-photon technologies. Jim Pawley offers a live cell course at both his home location of University of Wisconsin (Madison) and the University of British Columbia (Vancouver) while John Russ travels between North Carolina state and Denmark providing courses in image analysis and Optical/Video microscopy.

Unfortunately, the corporate answer to the microscopy education question is not so energetic. While most companies send their staff out for occasional courses, some companies such as $P \& G$ invite speakers in. Wright Patterson Research Labs is an exception. Their undergraduate level course has trained more than 300 researchers in microscopy since 1993.

Over the past few years, the microscope manufacturers have entered the training arena in a big way. EMS Diatome has offered courses in microtomy for some time and Ted Pella has recently teamed up with LEICA in the same arena. Photometrics is now offering special courses in camera technology; Media Cybernetics, both as an individual company and in conjunction with John Russ, provides extended workshops in image analysis; and Spectra-Tech continues its mini-university in FT-IR.

Short courses are also available from several professional societies. The Royal Microscopical Society has offered a wide range of courses for decades, primarily in the UK. The American Society for Materials has just moved to a new facility and offers courses in both sample preparation and microscopy with a healthy dose of morphological interpretation. For a quick overview, there are two, 2-day mini-symposia at the Eastern Analytical Symposium (Nov 14-19, Somerset, NJ) and for 3 days of total immersion, there is the American Chemical Society's "Applied Optical Microscopy" course, headed into its $18^{\text {th }}$ year next Spring.

No mention of short courses would be complete without reference to the McCrone Research Institute in Chicago. The premier example of consultant-based training, the Institute offers 75 courses, ranging between 3 and 5 days in length, from one of six full-time instructors. They specialize in Polarized Light Microscopy (PLM), conventional light microscopy, SEM, FTIR, and asbestos analysis. For paint, particles, and fibers, this is the place to go. Two other consulting groups, ProTrain (Steve Chapman) and SEMTraining (Bob Jernigan) focus on on-site SEM training, while Microscopy/Microscopy Education's staff of 24 consultants provide customized, on-site training in all areas of microscopy, from light and SEM to confocal, atomic force, and image analysis. MME also has specialists who cover a broad range of disciplines, from food and biological applications to polymers and semiconductors.

Two programs just for kids warrant special mention. Caroline Schooley's energetic efforts have brought together the Lawrence Hall of Science at UC/Berkeley with the Microscopy Society of America to form MICRO: Microscopy in Curriculum --- Research Outreach. MICRO's goal is to put MSA microscopists, teaching materials, and microscopes in middle schools nationwide and it has been successful. There are now hundreds of MSA microscopists volunteering time in local schools and, in 1998, MICRO produced the GEMS program: a textbook and teacher's workshop series.

\section{REVOLUTION}

The new spectra and image acquisition software program with the features you demand from 4 pi Analysis, Inc.

- Mixed acquisition of secondary and backscattered electron images, absorbed current images, EBIC images/linescans, CL images, WDS maps, x-ray maps/ linescans, color x-ray maps

- Real-time image and spectrum updates during acquisition

- Video signal scaling: none, max-min, log-scale, custom power-law

- Micron/magnification marker superimposed on image or below image

- Save full spectrum at every pixel - Auto-calibration of x-ray spectral energy

- X-ray linescans - Slow x-ray mapping • Fast $x$-ray mapping - SEM linescans

- and more!

\section{Digital Imaging \& EDS systems and upgrades}

\section{High-resolution Gresham x-ray detectors}
FLAME-the EDS acquistion and analysis software that's easy to learn and use, qual and quant

\section{Visit 4 pi at M\&M '99, booth no. 52e}

E-mail: sales@4pi.com Web: www.4pi.com Voice: 919-489-1757 
The Telepresence Microscopy Lab (TPM) at Argonne National Laboratories is the second program. Initiated and run by Dr. Nestor Zaluzec, the TPM actively solicits science projects which will use their Advanced Analytical Electron Microscope. Any interested science class can submit a proposal for an online experiment which can be watched over the internet. There is no charge and the only limit is the equipment available at the TPM lab. Everyone is equal: sixth grader and senior alike. If the proposal from your school does not win, you can still watch. And if a particular school is currently not hooked up to the Internet, Dr. Zaluzec will find a way to hook it up, even if only temporarily.

\section{In Summary}

As an analytical discipline, microscopy is alive and actively growing. Our challenge for the $21^{\text {ST }}$ century will be to take advantage of existing resources and to expand other opportunities which provide high quality education in microscopy and the related analytical and digital techniques. Training is just not sufficient in this environment.

As microscopy becomes more completely integrated into the analytical scheme, microscopists, even if they are just using microscopy as a simple tool, need to understand principles and relationships. The microscope has become the front end of an imaging system and we need to be educated on all aspects of that system.

About the author:

Ms. Foster heads Microscopy/Marketing \& Education, a na-

Lakefield Research Limited is a growing multidisciplinary metallurgical testing laboratory serving the metals and minerals industries, as well as the growing field of analytical and environmental testing. Lakefield Research is located in Lakefield, Ontario, Canada, with satellite operations in Timmins, Chile, Brazil, Peru and South Africa.

Reporting to the Manager of Mineralogical Services, the candidate will have a strong technical and operational knowledge of electron microprobe analysis. Experience with a JEOL 733 Superprobe / Tracor Northern Microanalyzer, would be an asset. You will be part of a dynamic team providing technical support and expertise to the exploration and mining industry at the head office in Lakefield, Ontario. Knowledge of mineral chemistry, QA/QC protocols and data handling for this Guide 25 accredited laboratory is strongly recommended.

A self-motivated, analytical thinker with strong organizational, trouble-shooting and project management skills, as well as the ability to grow the business, is essential. A university degree in a related discipline (geology, chemistry) is required. Salary and position will commensurate with experience. Please reply in confidence by August 31 , 1999 to:

\section{Shelley Kocjan, Human Resources Co-ordinator Lakefleld Research Limited \\ P.O. Box 4300 Lakefield, Ontario KOL $2 \mathrm{HO}$ \\ Fax \# 705-652-6365 e-mail: skocjan@lakefield.com}

tional consortium of microscopists who provide market research as well as customized, on-site training to the microscopy industry. Address: 125 Paridon Street, Suite 102, Springfield, MA 01118. PH: (413)746-6931 FX: (413)746-9311 email: mme@map.com

\section{Sales Engineer Position:}

Offering a unique opportunity to an energetic, selfstarter to manage the expansion of a market leading database firm for the East Coast. The position requires good people skills and the ability to conduct professional and technical sales. Knowledge of Windows platforms, imaging, databases and the Intranet would be a plus for any candidate. The position requires working with large Semiconductor, Pharmaceutical, Agriculture and Research companies in designing, equipping and project managing large installations. The position will also involve selling standard product line items.

The successful candidate will be involved in establishing new dealers and strategic partners along the East Coast Travel is required as well as assisting with shows and meetings. This position provides a salary, commissions, expenses, and health plus a car allotment.

Please send resumes in confidence to jhilton@rmii.com

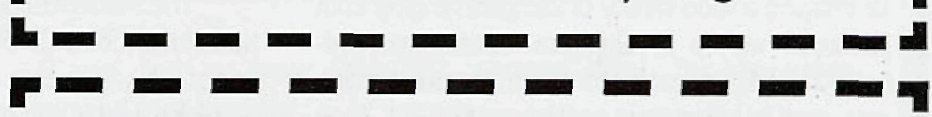

Best Quality, Best Price Microscope Bulbs Osram Mercury HBO 100, only $\$ 107.99$

Osram Mercury HBO 103, only $\$ 116.99$

Osram Xenon XBO75 Ozone Free, only $\$ 132.99$

2 bulb minimum - add $\$ 5.00$ per bulb for single orders

Shipping/handling/insurance from stock only $\$ 4.95$

Telephone or On-Site Technical Support Upon Request: $\$ 42.50$

\section{Best Quality, Best Price Objective Repair \\ Inside/Outside Oil Removal per Objective only $\$ 59.99$ \\ If not repairable, shop fee only $\$ 24.99$ \\ Return shipping/handling/insurance $\$ 14.95$ \\ Sciscope Instrument Company \\ Leica Kodak Sony Osram Dealer \\ Mail orders: Box 2237, lowa City, lowa 52244 USA USA telephone orders: 1-800-55-MICRO \\ Overseas telephone orders: $+319-338-1107$}

Fax orders: 1-319-338-3954 Internet orders: www.sciscope.com

*Include your Visa, Master Card or American Express information 